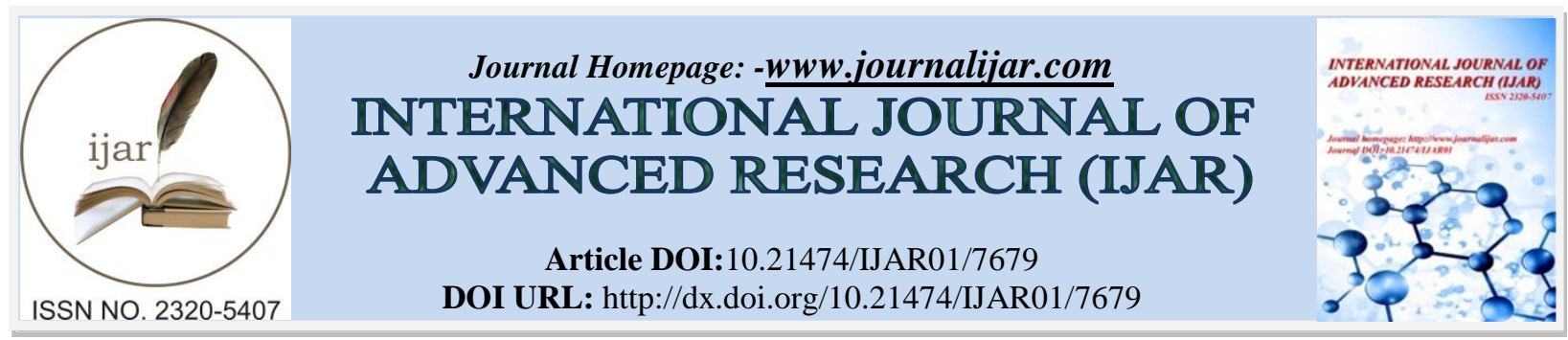

RESEARCH ARTICLE

\title{
ANATOMICALVARIATIONS AND ITS CLINICAL SIGNIFICANCE IN VERTEBROBASILAR SYSTEM - A CADAVERIC STUDY IN THE INDIAN POPULATION.
}

Dr.Murugesan Govindarajan $\mathrm{MCh}^{1}$ and Dr.N.Vijayeswaran M.S.,MCh${ }^{2}$.

1. Associate Professor of NeuroSurgery, Department of Neurosurgery, Coimbatore Medical College and Hospital ,Coimbatore-18.

2. Resident ,Department of Neurosurgery ,Coimbatore Medical College And Hospital ,Coimbatore-18.

\section{Manuscript Info}

Manuscript History

Received: 06 July 2018

Final Accepted: 08 August 2018

Published: September 2018

Keywords:-

Basilar artery, vertebral artery, microsurgical anatomy.

\section{Abstract}

Aim: To study the microsurgical anatomy and variations in the vertebrobasilar system of the Indian population and its clinical significance.

Materials and Methods: We have studied 40 cadaveric brain specimens in the forensic department at our Coimbatore Medical College Hospital.Microsurgical dissection was carried out and length and diameter of vertebrobasilar artery and its major branches and its associated anomalies were also recorded.

Results: The mean diameter of right vertebral artery(VA) was $3.01 \mathrm{~mm}$ and $3.3 \mathrm{~mm}$ on the left. Mean angle of fusion is $53^{\circ}$. The diameter of basilar artery ranged from $3-4.7 \mathrm{~mm}$ (mean $3.9 \mathrm{~mm}$ ) and length varied from $22-41.2 \mathrm{~mm}$ (mean $35.55 \mathrm{~mm}$ ). No fenestrations or duplication were noted in our study. Variations in VA caliber between both sides were noted. The diameter of the Anterior Inferior Cerebellar artery (AICA) varied from being 0.6-1.42 mm (mean $1.1 \mathrm{~mm}$ ). Superior Cerebellar Artery (SCA) arises very close to basilar bifurcation.No fetal Posterior cerebral artery(PCA) was noted.

Conclusion: The understanding of micro vascular anatomy of vertebrobasilar system and its variations is of utmost importance for safe surgery.

Copy Right, IJAR, 2018,. All rights reserved.

\section{Introduction:-}

The microsurgical anatomy of the vertebrobasilar circulation is very complex and variable ${ }^{1}$.Surgical approach to this area still remains a significant technical challenge for any neurosurgeon and risky due to the presence of the important neurovascular structure and the surgical field is limited within a deep and narrow operating corridor.

Posterior circulation is the most complex arterial system of the brain ${ }^{1}$. Thorough knowledge of the microvascular anatomy is very essential for the operating surgeon to choose the ideal technique in order to avoid any catastrophe during the surgery and to give the best possible functional outcome for the patients.

Various studies have been conducted in different countries on vertebrobasilar system and a few studies were done in the Indian population as well. With these studies as background we have analysed the microvascular anatomy and variations in vertebrobasilar system in the Indian population. 


\section{Materials and Methods:-}

Forty brains were studied from cadavers fulfilling the selection criteria from our institution in the forensic department. The age of the cadavers ranged from 30 to 72 years with a mean of 55 years. 28 cadavers were males and 12 were females. The skull was skeletanised and drilled and the base of the brain dissected without disturbing the vertebrobasilar system at the level of cervical cord level including around $1-1.5 \mathrm{~cm}$ of the vertebral artery (VA) and its branches. The internal carotid dissected before its bifurcation. We have injected $50 \mathrm{ml}$ of red poster colour dye into the vertebral artery. The retrieved specimen was subjected to morphometric analysis and all the findings were recorded and photographed.

\section{Results:-}

The mean diameter of right vertebral artery was $3.01 \mathrm{~mm}$ and $3.3 \mathrm{~mm}$ on the left (Table 1). The vertebrobasilar junction was at the level of pontomedullary junction. Mean angle of fusion of two vertebral arteries is $53^{\circ}$. No fenestrations or duplication were noted in our study. Fusiform aneurysm was noted in a left vertebral artery (fig.1). Variations in VA caliber between both sides were noted. Vertebral artery hypoplasia was noted in 5 cases(fig 2).

The diameter of the basilar artery range from 3 to $4.7 \mathrm{~mm}$ with a mean of $3.9 \mathrm{~mm}$ and length varied from 22 to 41.2 $\mathrm{mm}$ with mean of $37.06 \mathrm{~mm}$ (Table 2). The basilar bifurcation is $2-5 \mathrm{~mm}$ below the mammillary body.The straight course in prepontine sulcus maintained in $80 \%$ of specimens. No fenestration, duplication, triplication or hypoplasia of basilar artery were noted in our study.

The distance between the basilar bifurcation andAnterior Inferior Cerebellar Artery(AICA) origin is $0.5-3 \mathrm{~mm}$ with the average distance of $2.5 \mathrm{~mm}$ on right and $2.3 \mathrm{~mm}$ on the left.The diameter of the anterior inferior cerebellar artery range from 1-2 mm, with mean of $1.1 \mathrm{~mm}$. The numbers of paramedianpontine branches ranged from 1-5 in numbers and the circumflex pontine branches ranged between 1-4 .

The origin of superior cerebellar artery (SCA) was just below basilar bifurcation (range 1-2mm). The average diameter of the SCA ranged from 1-4mm, the mean diameter were $2.1 \mathrm{~mm}$ on both sides.

The common bifurcation of basilar artery to posterior cerebral artery (PCA) was below the mammillary body .The PCA arises at basilar bifurcation and was joined by the posterior communicating artery (PComA) at lateral margin of interpeduncular cistern. The length of the P1 segment of PCA was 3-6 mm with mean 3.1 on both sides(fig 3). The diameter PCA on the right side is $1-5 \mathrm{~mm}$ (mean $3.08 \mathrm{~mm}$ ) and on left side is $1-5 \mathrm{~mm}(\mathrm{mean} 3.1 \mathrm{~mm}$ ). In our study, no fetal PCA was found.

Table 1:-Morphometric analysis results (in $\mathrm{mm}$ )

\begin{tabular}{|c|c|c|c|c|c|c|c|c|c|c|c|c|}
\hline & \multicolumn{2}{|c|}{$\begin{array}{l}\text { Vertebral } \\
\text { artery diameter }\end{array}$} & \multicolumn{2}{|c|}{ Basilar artery } & \multicolumn{2}{|c|}{$\begin{array}{l}\text { PICA } \\
\text { diameter }\end{array}$} & \multicolumn{2}{|c|}{$\begin{array}{l}\text { AICA } \\
\text { diameter }\end{array}$} & \multicolumn{2}{|c|}{$\begin{array}{l}\mathrm{SCA} \\
\text { diameter }\end{array}$} & \multicolumn{2}{|c|}{$\begin{array}{l}\text { PCA } \\
\text { diameter }\end{array}$} \\
\hline $\begin{array}{l}\text { Present } \\
\text { Study }\end{array}$ & 3.013 & 3.36 & 3.90 & 37.065 & 1.22 & 1.27 & 1.1 & 1.1 & 1.22 & 1.27 & 3.08 & 3.10 \\
\hline
\end{tabular}

Table 2:-Average dimensions of vertebral and basilar artery from other studies (in $\mathrm{mm}$ )

\begin{tabular}{|c|c|c|c|c|c|c|c|}
\hline Name of the author & $\begin{array}{l}\text { Length } \\
\mathrm{mm} \\
\text { Range }\end{array}$ & $\begin{array}{l}\text { isilar artery in } \\
\text { Average }\end{array}$ & $\begin{array}{l}\text { Diamete } \\
\text { mm } \\
\text { Range }\end{array}$ & $\begin{array}{l}\text { silar artery in } \\
\text { Average }\end{array}$ & $\begin{array}{l}\text { Dial } \\
\text { arte } \\
\text { Ran } \\
\mathrm{R} \\
\end{array}$ & $\begin{array}{l}\text { ter } \\
\text { in } \mathrm{m} \\
\mathrm{L}\end{array}$ & vertebral \\
\hline Pai et al $^{1}$ & $24-35$ & 24.9 & $3-7$ & 4.3 & 2.9 & 3.4 & 3.15 \\
\hline Idowu et al $^{2}$ & $20-40$ & 31.42 & $2.5-5.5$ & 3.82 & & & 2.98 \\
\hline Present study & $22-37$ & 28.5 & $3-6.2$ & 4.5 & 2.9 & 3.5 & 3.05 \\
\hline
\end{tabular}


Table 3:-Comparison of dimensions of vertebrobasilar system with other studies (in mm )

\begin{tabular}{|c|c|c|c|c|c|c|c|c|c|c|c|c|c|}
\hline \multirow{2}{*}{$\begin{array}{l}\text { STUDY } \\
\text { Present study }\end{array}$} & \multirow{2}{*}{$\begin{array}{l}\text { COUNTRY } \\
\\
\text { INDIA } \\
\end{array}$} & \multicolumn{2}{|c|}{$\begin{array}{l}\text { VERTEBRAL } \\
\text { ARTERY } \\
\text { DIAMETER } \\
\text { Rt }\end{array}$} & \multicolumn{2}{|c|}{$\begin{array}{l}\text { BASILAR } \\
\text { ARTERY } \\
\text { DIAMETER } \\
\text { DIA /LENGTH }\end{array}$} & \multicolumn{2}{|c|}{$\begin{array}{l}\text { PICA } \\
\text { DIAMETER } \\
\mathrm{Rt} \quad \mathrm{Lt}\end{array}$} & \multicolumn{2}{|c|}{$\begin{array}{l}\text { AICADIAMETER } \\
\mathrm{Rt} \quad \mathrm{Lt}\end{array}$} & \multicolumn{2}{|c|}{$\begin{array}{l}\text { SCA } \\
\text { DIAMETER } \\
\mathrm{Rt} \quad \mathrm{Lt} \\
\end{array}$} & \multicolumn{2}{|c|}{$\begin{array}{l}\text { PCA } \\
\text { DIAMETER } \\
\text { Rt } \quad \text { Lt } \\
\end{array}$} \\
\hline & & 3.013 & 3.36 & 3.90 & 37.065 & 1.22 & 1.27 & 1.1 & 1.1 & 1.22 & 1.27 & 2.7 & 2.6 \\
\hline Pai et al ${ }^{1}$ & INDIA & 2.9 & 3.4 & 4.3 & 24.9 & 1.23 & 1.2 & 1.0 & 1.0 & 1.45 & 1.33 & 2.76 & 2.5 \\
\hline 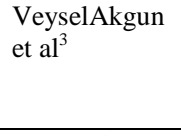 & TURKEY & 2.95 & 3.23 & & & 1.67 & 1.64 & 1.24 & 1.28 & 1.59 & 1.52 & 2.56 & 2.43 \\
\hline $\begin{array}{l}\text { Kawashima et } \\
\mathrm{al}^{4}\end{array}$ & JAPAN & & & & & 1.84 & & 1.34 & & 1.67 & & 2.13 & \\
\hline
\end{tabular}

Fig 1:-Fusiform aneurysm of Lt VA Atheroma in BA

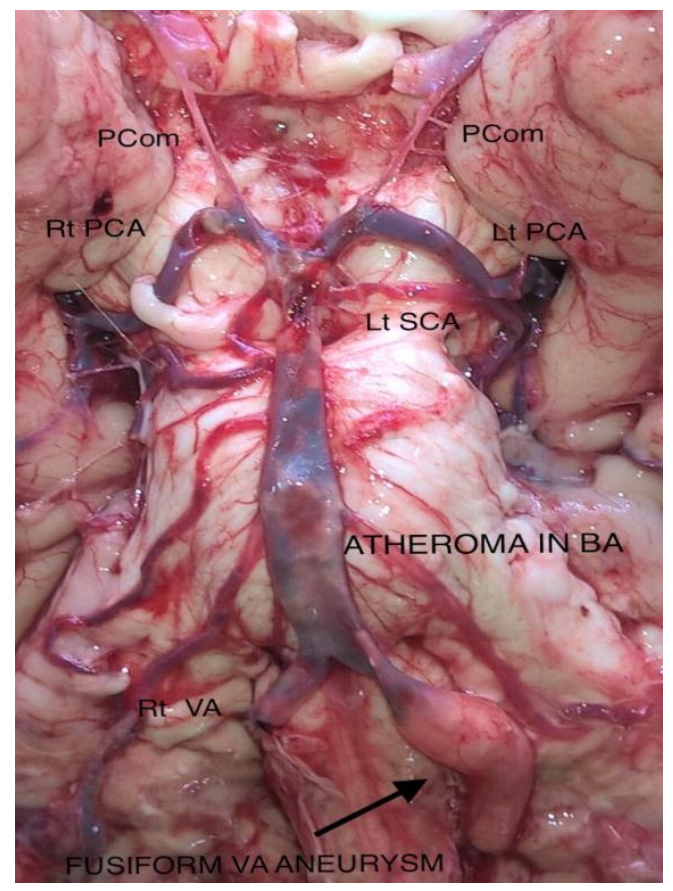

Fig 2:-Rt VA Hypoplasia Atheroma in Lt VA

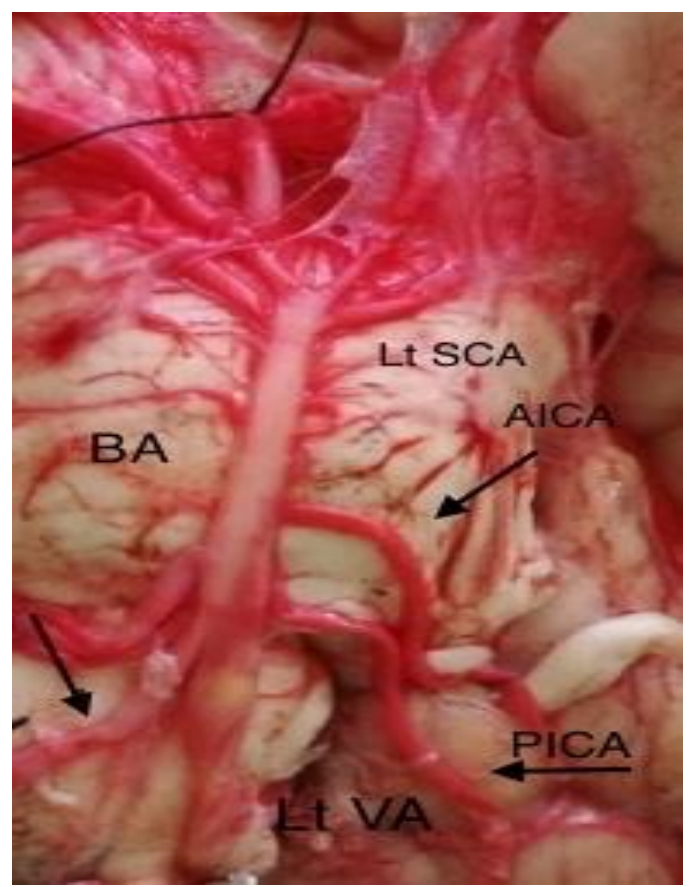


Fig 3:-Variable Left P1

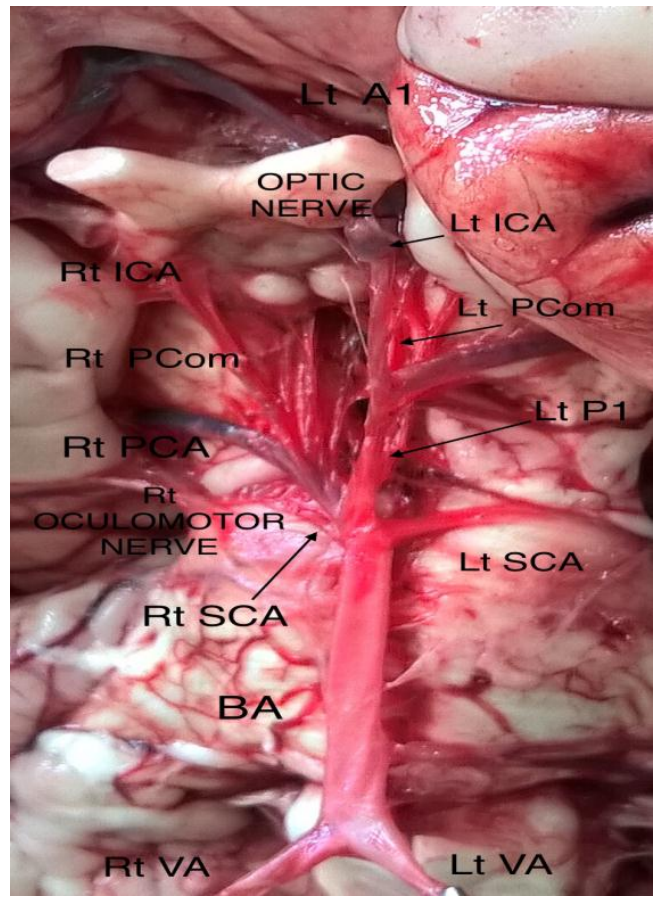

Fig 4:-Lateral view showing pontine br

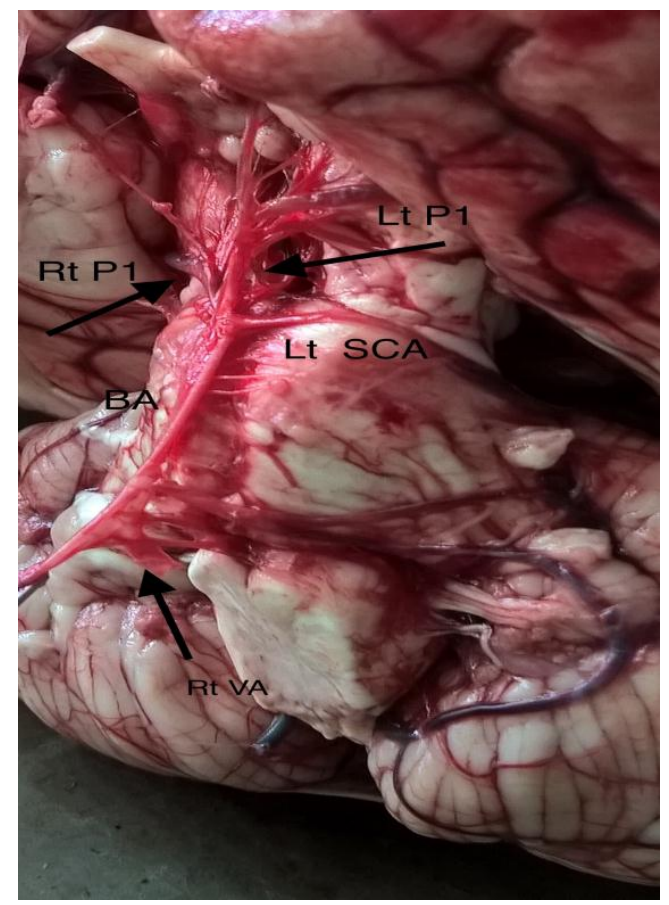

\section{Discussion:-}

\section{Vertebral Artery}

The Vertebral artery penetrate the atlanto-occipital membrane after they leave the foramen transversarium of the atlas and enters the posterior fossa through the foramen magnum and fuse together at the level of pontomedullary junction.

In our study, both VA were of same size in 32 specimens, and right VA hypoplasia noted in 5 cases associated with large vertebral artery on the left side. Asymmetry of vertebral arteries is quite common, but the amount of blood reaches the basilar artery remains constant due to the contralateral large vertebral artery ${ }^{5}$.Park et al stated that vertebral artery hypoplasia or asymmetry is frequently associated with posterior circulation stroke ${ }^{6,7}$.

Watanabe et $\mathrm{al}^{8}$ correlated asymmetry of vertebral artery to be one of the risk factors of pontine infarction on the side of small VA in the Japanese population.

Chaturvediet $\mathrm{al}^{9}$ suggested that a hypoplasticvertebrobasilar system was considered to be a predisposing factor in the posterior circulation ischemia. Fenestration and duplications were frequently associated with intracranial vascular abnormalities like AVMs and aneurysms. No fenestration or duplication was noted in our study.

An unruptured fusiform aneurysm was noted in the left VA (Fig 1). Fusiform aneurysms have a higher incidence in the posterior circulation, particularly along the vertebro-basilar artery, than the anterior circulation. Many of these fusiform aneurysms are the result of an arterial dissection, particularly along the VA.In our study, one fusiform aneurysm was found and was associated with atheromatous plaque.

\section{PICA}

Largest and most distal branch of VA, the PICA has a complex course with a tortuous and variable character ${ }^{10}$. The PICA arises from the vertebral artery near the inferior olive and passes posteriorly around the medulla. Average diameter in our study was $1.27 \mathrm{~mm}$ and ranged from $0.68-1.8 \mathrm{~mm}$. The proximity of the telovelotonsillar segment of the two PICA allows PICA- PICA in situ bypass . 


\section{Basilar Artery}

Fenestration caused by incomplete fusion of parallel arterial segments of two longitudinal neural arteries (LNA) is associated with high incidence of aneurysm.

Basilar artery usually starts at the lower margin of the pontomedulary sulcus. The basilar artery becomes more tortuous in the old age. The perfectly straight course of the artery is present in $80 \%$ of the cases and the midline course of the artery deviated often towards left in old age. The proximal basilar artery is usually concave toward the larger vertebral artery but in our study even in hypoplasia of right VA no concavity was found.

Hong $\mathrm{JM}$ et $\mathrm{al}^{11}$ found that pontine infarcts more frequently occurred opposite to the side of BA curvature and PICA territory infarcts were more frequent on the hypoplastic VA side. Persistent carotid and basilar anastomosis such as primitive trigeminal, otic, hypoglossal or proatlantic arteries may fill the basilar artery from the carotid circulation. No such abnormalities were noted in our study.

The diameter of the basilar artery ranges from $2.7-4.3 \mathrm{~mm}$. Basilar artery supplies pons by paramedial and circumferential perforating arteries(fig 4).The BA is a favoured site for atherosclerotic changes ( Fig 1) among the intracranial vessels, and the clinical manifestations of BA occlusive disease vary according to the site and nature of the vascular compromise.

Basilar top aneurysm occurs at the bifurcation of basilar artery into PCA and projects superiorly.The common land mark for basilar bifurcation is opposite to the interpeduncular fossa. The bifurcation aneurysms are best approached through the sub temporal craniotomy to avoid brain stem perforators. In our study, all the perforators arised from the superior aspect of basilar artery at the P1 segment.Many perforators arised from the posterolateral surface of basilar artery. No perforator was seen arising from the anterior surface of basilar artery. Care should be given to avoid perforator compromise in basilar top aneurysm surgery to avoid catastrophic complications.

Posterior basilar bifurcation aneurysms have poor prognosis, as the perforators usually arise in posterior surface. Anterior projection aneurysms have better prognosis as there are no perforators. Most of the perforators are concentrated close to the P1 segment and these perforators enter the interpeduncular fossa and terminate in the medial midbrain.

\section{The Superior Cerebellar Artery}

Superior cerebellar artery is most consistent in origin and arises near the bifurcation. Oculomotor nerve passes in between SCA and PCA. Neurovascular conflict between SCA and trigeminal nerve causes trigeminal neuralgia. In our study, there was no neurovascular conflict at the root entry zone of trigeminal nerve.

\section{AICA}

Anterior inferior cerebellar artery arises from the basilar artery. AICA origin is calculated from the vertebrobasilar junction. When one cerebellar artery is small the adjacent ipsilateral or contralateral arteries are larger. According to Fuji and Rhoton the AICA is hypoplastic in $20 \%$ of cases with corresponding enlargement of the ipsilateral PICA or rarely the theipsilateral SCA.

\section{PCA}

The segment of posterior cerebral artery from its origin to the posterior communicating artery is termed P1 segment.The PCA/PCOA junction occurs at the lateral margin of the interpeduncular cistern. In fetal PCA, P1 is vestigial and the PCA gets the blood supply from ICA. In our study, disproportionate P1 segment was noted.

The size of the P1 segment depends on the extent to which the posterior comm artery contributes to blood flow in the distal PCA.Usually the P1 segment of posterior cerebral artery is larger than posterior communicating artery.

In the presence of FPCA, thromboembolism in the anterior circulation may result in paradoxical PCA territory infarction with or without concomitant infarction in the territories of the middle (MCA) or the anterior (ACA) cerebral artery. 
The average length of the P1 was 5-10 mm (mean $6.0 \mathrm{~mm}$ ) on the right side and $6-11 \mathrm{~mm}$ (mean $7.0 \mathrm{~mm}$ ) on the left side. The average diameter of the PCA was $3.1 \mathrm{~mm}$ on both sides.

\section{Conclusion:-}

The understanding of micro vascular anatomy of vertebrobasilar system and its variations is of utmost importance for safe surgery.Even though pre-operative angiogram allow a precise and detailed evaluation of vertebrobasilar system, a thorough knowledge of microneurosurgical anatomy of vertebrobasilar system and its variations is needed when operating within a deep and narrow operating corridor.

\section{References:-}

1. Pai BS, Varma RG, Kulkarni RN, Nirmala S, Manjunath L C, Rakshith S. Microsurgical anatomy of the posterior circulation. Neurol India 2007;55:31-41

2. Idowu OE, MalomoAO,AkangEU.Surgical Anatomy of the VertebrobasilarTerritory and Posterior Circle of Willis.West African Journal of Medicine. 2010;29(4):230-34.

3. VeyselAkgun, Bilal Battal, YalcinBozkurt, et al., "Normal Anatomical Features and Variations of the Vertebrobasilar Circulation and Its Branches: An Analysis with 64-Detector Row CT and 3T MR Angiographies," The Scientific World Journal, vol. 2013, Article ID 620162, 7 pages, 2013

4. M. Kawashima, A. L. Rhoton, N. Tanriover, A. J. Ulm, A. Yasuda, and K. Fujii, "Microsurgical anatomy of cerebral revascularization. Part II: Posterior circulation," Journal of Neurosurgery, vol. 102, no. 1, pp. 132-147, 2005

5. GillilanLA.Anatomy and embryologyofthe arterial system of thebrain stem andcerebellum. In:Vinken PJ, Bruyn GW(editors), Handbookof clinicalneurology,Amsterdam,Netherlands,1975,pp.24-44.

6. Park JH, Kim JM, RohJK.Hypoplasticvertebralartery:Frequency and associationswithischemicstroke territory. J NeurolNeurosurg Psychiatry.2007; 78: 954-958.

7. PerrenF,Poglia D, Landis T, SztajzelR.Vertebral artery hypoplasia:Apredisposingfactor for posterior circulation stroke?Neurology. 2007; 68: 65-67

8. Watanabe M, Takahashi 78: A, Neurol 98789 . HashizumeMotegiY ,Furuse K . Y, The correlation between pontine study. 70812 .

9. Chaturvedi S, Lukovits TG, Chen W,GorelickPB.Ischemia in the territory of ahypoplastic vertebrobasilarsystem.Neurology.1999; 52: 980-983.

10. Rodriguez-Hernandez A, Rhoton AL Jr. Lawton MT. Segmental anatomy of cerebellar arteries:a proposed nomenclature . Laboratory investigation. J neurosurgery 2011;115:387-397.

11. Hong JM, Chung C-S, Bang OY, Yong SW, Joo IS, Huh K. Vertebral artery dominance contributes to basilar artery curvature and peri-vertebrobasilarjunctional infarcts. Journal of Neurology, Neurosurgery, and Psychiatry. 2009;80(10):1087-1092. doi:10.1136/jnnp.2008.169805. 